\title{
The place of early social assessment in the management of surgical patients
}

\author{
T. BATES* $\dagger$ \\ F.R.C.S.
}

\author{
A. BEHR \\ C.Q.S.W.
}

\author{
K. Menzies* \\ F.R.C.S.
}
M. RENDALL
F.R.C.S.

\section{*Department of Surgery, Guy's Hospital, London SE1 $9 R T$ and St Olave's Hospital, London SE16 2TS}

\begin{abstract}
Summary
Twenty-four percent of bed-days were occupied by patients whose discharge from hospital was delayed for social or geriatric reasons in a bed-usage survey carried out on surgical patients during a three-month period of 1973.
\end{abstract}

By early social assessment with the regular help of a medical social worker it was possible to reduce such delays to $16 \%$ in a similar study during the same period of 1974. The at-risk patients were the elderly admitted as an emergency and the present policy contributed particularly to the overall care of this group.

\section{Introduction}

The efficient use of acute surgical beds requires continual planning which is often frustrated by unexpected delays for administrative or social reasons quite apart from medical or surgical complications. St Olave's is a small, general hospital with a catchment population which includes a considerable proportion of elderly people living in poor housing conditions, and also serves as the general surgical outlet of New Cross Hospital which has geriatric as well as general medical beds. This seemed to be reflected by the large number of longstay patients on the surgical wards.

A bed-usage survey was carried out during 3 months of 1973 in an attempt to define the causes and the extent of delay in the investigation, treatment and discharge of surgical patients. Analysis of this survey showed that the principal cause of a prolonged hospital stay after admission to a surgical ward was delay in discharge due to social problems in the elderly.

It was also found that few of the patients whose discharge had been delayed for social reasons had been formally referred to the medical social worker (M.S.W.) and that referrals from the surgical wards were only a third of the number made for a similar number of medical patients in the same hospital. It

†Present address: Ashford Hospital, King's Avenue, Ashford, Kent TN23 1LX. was felt that a greater awareness by the surgical team of potential social problems early in the patients' admission might reduce the delay in their discharge from hospital.

A further survey was therefore carried out during the same period the following year (1974) during which time a M.S.W. attended one surgical round each week and therefore saw all patients either before or just after operation.

\section{Patients and methods}

All routine and emergency admissions to one (of three) general surgical firm at St Olave's Hospital, during the 3 months April, May and June, 1973, were considered in the first study. The patient's age, sex, the nature of the operation or diagnosis and the dates of admission and discharge were entered on a pro forma. The hospital has a system of progressive patient care under which the post-operative patient may progress from the heavy-nursingdependency ward to the intermediate-dependency ward and finally to the low-dependency (homeward bound) ward before discharge. The ward the patient was on was noted for each day of admission.

In order to identify the cause of any delay in the patient's investigation, operation or subsequent discharge, eleven categories detailed in Table 1 were entered on the pro forma, where appropriate, for each day of admission. The number of bed-days occupied by patients who could have been investigated or treated at home without hardship was recorded.

During the period of this investigation there were five amputees on the intermediate male surgical ward, two of whom were under the care of the firm being studied. Since they were a particular long-term medical-social problem it was decided to consider these cases separately.

Those patients admitted as day-cases for minor surgery were also reviewed separately but no other patient was excluded from this study.

The second study was made during the same 
TABLE 1. Comparison of the causes of delay in patients' investigation, operation or discharge during the two periods of study

\begin{tabular}{|c|c|c|c|c|c|c|}
\hline \multirow[b]{2}{*}{ Causes of delay } & \multicolumn{2}{|c|}{$\begin{array}{l}\text { Number of } \\
\text { patients }\end{array}$} & \multicolumn{2}{|c|}{$\begin{array}{l}\text { Number of } \\
\text { bed-days }\end{array}$} & \multicolumn{2}{|c|}{$\begin{array}{l}\text { Delay as percent total } \\
\text { bed-days }\end{array}$} \\
\hline & 1973 & 1974 & 1973 & 1974 & 1973 & 1974 \\
\hline $\begin{array}{l}\text { Investigation could have been } \\
\text { done as out-patient } \\
\text { Delay for diagnostic X-rays } \\
\text { Delay for other investigations } \\
\text { Delay awaiting theatre time } \\
\text { Delay by junior doctors } \\
\text { Delay by nursing staff } \\
\text { Delay by consultant staff } \\
\text { Delay awaiting surgeon/ } \\
\text { anaesthetist }\end{array}$ & $\begin{array}{r}2 \\
5 \\
2 \\
10 \\
2 \\
1 \\
3\end{array}$ & $\begin{array}{l}0 \\
4 \\
0 \\
6 \\
5 \\
0 \\
7\end{array}$ & $\begin{array}{r}7 \\
40 \\
13 \\
24 \\
5 \\
2 \\
22\end{array}$ & $\begin{array}{r}0 \\
20 \\
0 \\
23 \\
16 \\
0 \\
32\end{array}$ & (117) $9 \%$ & (105) $8.4 \%$ \\
\hline $\begin{array}{l}\text { Delay in discharge due to } \\
\text { social factors alone } \\
\text { Delay awaiting geriatric } \\
\text { assessment or transfer }\end{array}$ & 22 & 2 & $\begin{array}{r}207 \\
94\end{array}$ & 149 & (301) $24 \%$ & (202) $16 \%$ \\
\hline $\begin{array}{l}\text { Delay due to surgical } \\
\text { complications }\end{array}$ & 10 & 8 & 186 & 194 & $15 \%$ & $15.4 \%$ \\
\hline Total & 74 & 79 & 1248 & 1254 & (604) $48 \%$ & (501) $40 \%$ \\
\hline
\end{tabular}

3 months of 1974 using the same pro forma and, as far as possible, the same criteria for inclusion in the various categories of delay.

A medical social worker attended one round every week and each patient's eventual discharge from hospital was discussed. If there appeared to be any potential social difficulty the M.S.W. subsequently interviewed the patient and his or her relatives and if necessary made a visit to the home. If it became obvious that long-term geriatric care might be necessary a request for a geriatric consultation was made as early as possible. In addition, a careful social history was taken from each patient and his or her relatives and friends by the admitting housesurgeon and if there appeared to be any immediate problem the M.S.W. was contacted on the same day. The amputees and patients admitted for day-case surgery were also considered separately in the second study.

The two periods of study were compared with respect to the number and sex of patients in each decade, for the type of operation or treatment and for the number of days spent on each type of ward. A comparison of the causes of delay in the two periods was then made.

\section{Results}

There were seventy-four patients admitted during the first period of study and seventy-nine during the second, excluding the day cases and amputees. The two periods were well matched for the number of patients in each decade (Table 2). In both groups, $50 \%$ were aged 60 years or over, although the proportion of females was higher in 1974 (57\% compared with $46 \%$ in 1973 ).
TABLE 2. Comparison of patients' age by decade with delay in discharge for social and geriatric reasons in 1973 and 1974

\begin{tabular}{|c|c|c|c|c|c|c|}
\hline \multirow{2}{*}{$\begin{array}{c}\text { Age } \\
\text { (years) }\end{array}$} & \multicolumn{2}{|c|}{$\begin{array}{c}\text { No. of } \\
\text { patients }\end{array}$} & \multicolumn{2}{|c|}{$\begin{array}{l}\text { No. of } \\
\text { patients } \\
\text { requiring } \\
\text { social stay }\end{array}$} & \multicolumn{2}{|c|}{$\begin{array}{l}\text { Bed-days } \\
\text { social care }\end{array}$} \\
\hline & 1973 & 1974 & 1973 & 1974 & 1973 & 1974 \\
\hline Under 20 & 10 & 13 & 1 & 1 & 1 & 1 \\
\hline $30-39$ & 9 & 7 & 2 & 0 & 10 & 0 \\
\hline $40-49$ & 7 & 7 & 1 & 0 & 10 & 0 \\
\hline $50-59$ & 11 & 13 & 3 & 2 & 24 & 43 \\
\hline $60-69$ & 16 & 19 & 8 & 2 & 78 & 23 \\
\hline $70-79$ & 17 & 12 & 7 & 2 & 93 & 35 \\
\hline $80+$ & 4 & 8 & 3 & 2 & 85 & 100 \\
\hline Total & 74 & 79 & 25 & 9 & 301 & 202 \\
\hline
\end{tabular}

It was difficult to compare the severity of illness or operations during the two periods (Table 3). The numbers of patients in each group were comparable except for three patients in the 1973 period admitted for radiotherapy or terminal care (not counted as $\exists$ social admissions). However, the mean length of stay in those patients undergoing operation in the 1974 period was slightly longer.

The pattern of ward usage was very similar allowing for the greater number of females in the second period (Table 4).

Administrative delays were responsible for $9 \%$ of o bed-days in hospital in 1973 and this figure was $N$ virtually unchanged at $8.4 \%$ in 1974 (Table 1). స్ల Time spent awaiting diagnostic X-rays, theatre time and consultant opinion were the three most common causes of delay in the investigation or treatment of $\stackrel{\mathbb{D}}{\overparen{D}}$ patients. Discharge home was delayed by post- $\stackrel{?}{?}$ operative complications for the same length of time in both groups ( $15 \%$ of the total bed-days). 
TABLE 3. Length of hospital stay compared with type of admission in 1973 and 1974

\begin{tabular}{|c|c|c|c|c|c|c|}
\hline \multirow[b]{2}{*}{ Type of admission-operation } & \multicolumn{2}{|c|}{$\begin{array}{l}\text { No. of } \\
\text { patients }\end{array}$} & \multicolumn{2}{|c|}{$\begin{array}{c}\text { Total no. } \\
\text { of days }\end{array}$} & \multicolumn{2}{|c|}{$\begin{array}{l}\text { Mean no. of } \\
\text { days (range) }\end{array}$} \\
\hline & 1973 & 1974 & 1973 & 1974 & 1973 & 1974 \\
\hline Minor operation & 27 & 34 & 130 & 194 & $\begin{array}{r}4 \cdot 8 \\
(3-9)\end{array}$ & $\begin{array}{c}5 \cdot 7 \\
(2-23)\end{array}$ \\
\hline Intermediate operation & 8 & 7 & 73 & 94 & $\begin{array}{c}9 \cdot 1 \\
(3-14)\end{array}$ & $\begin{array}{c}13 \cdot 4 \\
(6-40)\end{array}$ \\
\hline Major operation & 21 & 22 & 640 & 726 & $\begin{array}{c}30 \\
(11-98)\end{array}$ & $\begin{array}{c}33 \cdot 1 \\
(11-100)\end{array}$ \\
\hline No operation -investigation, etc. & 15 & 16 & 278 & 240 & $\begin{array}{l}19 \\
(3-56)\end{array}$ & $\begin{array}{c}15 \\
(2-56)\end{array}$ \\
\hline Radiotherapy & 1 & 0 & 85 & 0 & 85 & $\mathbf{0}$ \\
\hline Terminal care & 2 & $\mathbf{0}$ & 42 & 0 & $\begin{array}{l}42 \\
(9-33)\end{array}$ & 0 \\
\hline Total & 74 & 79 & 1248 & 1254 & $\begin{array}{l}17 \\
(3-98)\end{array}$ & $\begin{array}{l}16 \\
(2-100)\end{array}$ \\
\hline
\end{tabular}

TABLE 4. Pattern of ward usage comparing 1973 and 1974

\begin{tabular}{|c|c|c|c|c|c|}
\hline \multirow[t]{2}{*}{ Type of ward (nursing dependency) } & \multirow[t]{2}{*}{ Sex } & \multicolumn{2}{|c|}{$\begin{array}{l}\text { Total no. } \\
\text { of bed-days }\end{array}$} & \multicolumn{2}{|c|}{ Social/geriatric bed-days } \\
\hline & & 1973 & 1974 & 1973 & 1974 \\
\hline Heavy dependency & Mixed & 256 & 276 & 0 & 0 \\
\hline Intermediate dependency & Female & 398 & 491 & $137(34 \%)$ & $116(23.6 \%)$ \\
\hline Intermediate dependency & Male & 494 & 372 & $86(17 \%)$ & $40(11 \%)$ \\
\hline Low dependency & Mixed & 100 & 115 & $78(78 \%)$ & $46(40 \%)$ \\
\hline Total & & 1248 & 1254 & $301(24 \%)$ & $202(16 \%)$ \\
\hline
\end{tabular}

However, during the 1974 period the extent of delays due to social or geriatric problems was reduced from $24 \%$ to $16 \%$. This improvement appeared to be due partly to anticipating social problems and partly to earlier geriatric referral when this was appropriate.

Eighteen $(49 \%)$ patients aged 60 years or over, in the 1973 study, felt that they could no longer cope with their home conditions again when the time came for discharge from hospital. During the second period only six $(15 \%)$ of the over 60 's fell into this category.

The bed occupancy rate was approximately $70 \%$ during both periods although during 1973 this fell to $50 \%$ in the low-dependency ward (which is shared with medical patients). Emergency admissions accounted for $18 \%$ of patients in the first period and $30 \%$ in the second period. However, these patients accounted for $56 \%$ and $67 \%$ of the total bed-days used for social or geriatric care respectively. Approximately $75 \%$ of the emergency admissions were over the age of 60 in both periods compared with $50 \%$ over 60 taking all admissions.

During the first study period there were five amputees on the intermediate-dependency male surgical ward although all were admitted before April 1973. Two were under the care of the surgical firm being reviewed. One patient's discharge from the ward was delayed for 6 months after he was satisfactorily mobilized with a prosthesis because he was unable to reach his third floor flat which had no lift. Only after repeated application to the local housing department was a satisfactory ground floor flat made available. A 72-year-old bilateral amputee with unstable diabetes and blindness eventually died on the ward after 9 months. His home circumstances were satisfactory but every attempt to discharge him was deferred by recurrent chest infection. A second 70-year-old bilateral amputee was still on the ward during the second study-period, over a year after his admission, awaiting suitable sheltered accommodation.

During the second period, two amputees were admitted under the firm being studied. They were both men, aged 75 and 92 , and were in hospital for 28 and 38 days respectively. These patients were in acute surgical beds for a relatively short period of time because it was possible to transfer them back to long-stay beds, from which they had been referred for amputation, before adequate mobilization had been achieved. In all, the seven amputees present on the wards during the two periods of study occupied a hospital bed for 1540 days. The mean length of stay was 8 months.

The service provided by the Limb Fitting Centre at Roehampton was good, although application for an 
appointment at the time of amputation, to avoid delay, was often thwarted by delayed healing, and many appointments had to be cancelled.

Day cases were admitted to an investigation ward which is open 5 days a week. There were twenty-one such cases in the 3 months of 1973 and twenty-five in the same period of 1974. A similar number in both periods had a minor surgical procedure or endoscopy carried out, mostly under general anaesthetic. Four patients were unexpectedly kept overnight for observation in 1973 and one patient in 1974, but the arrangements for day cases were generally satisfactory.

\section{Discussion}

The catchment area of St Olave's Hospital consists mainly of the dockland area of Bermondsey and Deptford. Most of the docks have closed over the last 10 years and there has been little new industry to replace the employment they provided. One effect of this has been to produce an ageing population in an area with poor housing conditions. Hunt (1973) found that $35 \%$ of beds in surgical wards are occupied by patients over 65 and that this proportion is rising every year. Using the same criteria for the present study, $50 \%$ of beds were occupied by patients over 65 and it was this group principally whose discharge from hospital was delayed for social or geriatric reasons. Thus, although this problem was greater than that in most hospitals, it is one that is likely to increase in the future.

When the two three-month periods are compared, these delays seemed to be considerably reduced from $24 \%$ of the total bed-days, to $16 \%$ when a M.S.W. attended a ward round each week. This arrangement has long been a tradition in some hospitals but tends to become a formality, so that social problems are often not discussed until they threaten to delay the patient's post-operative discharge. In the present study each patient's social circumstances were discussed at the first ward round after admission in order that any necessary arrangements could be made well in advance. Attempts to make a social assessment before admission in elective cases meant that only $25 \%$ of the at-risk group were covered and it was found that the major problem lay with elderly patients admitted as an emergency.

It was in this group of patients that a social history taken at the time of admission proved most valuable. It was often possible to question relatives or friends, who might have been subsequently less available or forthcoming, to get a clear picture of the patient's home circumstances at the outset. In practice this was not found to be time-consuming and undoubtedly contributed to the overall care of the patient quite apart from any administrative considerations.
No attempt has been made to apply tests of statistical significance to the difference in social and 3 geriatric delays between the two periods studied. $\stackrel{\unrhd}{\complement}$ Although the two periods covered the same 3 months $\stackrel{c}{-}$ of successive years and the patients reviewed ap- $\overrightarrow{\vec{F}}$ peared to be evenly matched with respect to age and severity of operation, the numbers are relatively small등 and it is possible that unrecognized factors may have $\frac{\bar{\omega}}{\overline{0}}$ biased the study in favour of the second period. One $\vec{\varnothing}$ of the geriatric wards was closed in 1974 so that 2 transfer was more difficult, although consequent ${ }^{\infty}$ delays were less due to earlier application. $\overrightarrow{0}$

It can be argued that the improvement resulted $\overrightarrow{-}$ from a special effort over a short period of time and $\omega$ that with loss of enthusiasm the situation wouldo gradually revert to the previous level. However, this 3 . arrangement was used for the other two surgical of firms during the study and has subsequently been in? operation for 6 months since the completion of the study.

Some of the less tangible benefits of early social $\vec{\circ}$ assessment are probably just as important as the more economic factors that have been studied. $\vec{T}$ Reassurance that problems left at home after an $\mathbb{D}$ emergency admission have been or can be dealt with may do much to allay the patient's anxiety.

The problem of the amputee is an intractable ong. During both periods an early social assessment woㅕㅎ made but on the whole, medical recommendatio for improvement in housing conditions carry litte weight. Such recommendations are often relative, e. $\overrightarrow{\mathrm{g}}$. 옹 that a patient with a colostomy should have a bathroom, but for an amputee they may be absolute; if he lives up several flights of stairs without a lift, he $\stackrel{\varnothing}{\varnothing}$ cannot go home. Weaver and Marshall (1973) found $\overrightarrow{\vec{P}}$ that the average length of hospital stay for bilateral $\frac{\text { 일 }}{3}$ amputees was about 4 months although they also had an amputee in hospital for nearly 18 months before suitable accommodation was found.

It was not found possible to make a useful estimate 3 of the number of bed-days occupied by patients who $\dot{0}$ could have been investigated as an out-patient (Table 1). In the elderly, repeated ambulance jour- $\delta$ neys to hospital for a series of investigations may be distressing, whilst younger patients, who would far 웅 rather be at home, may be kept in hospital un- $\rightarrow$ necessarily. It was found, however, that some investigations could have been booked before the patient's admission. Delays for diagnostic X-rays and $\%$ other investigations were often prolonged by the $N$ week-end.

Delays caused by junior staff failing to arrange investigations or treatment were few but during the 0 first period the low bed-occupancy rate removed $\stackrel{D}{\Phi}$ much of the incentive to encourage early discharge $\stackrel{\infty}{\rightarrow}$ after operation or to foresee social problems which 7 might have been forestalled or tackled earlier. 
Similarly, with the progressive patient care system, the low bed-occupancy rate meant that there was little pressure on the medical staff to transfer patients to the lower dependency wards as soon as this became appropriate.

The problem of elderly patients who are admitted as surgical emergencies is likely to increase and it is felt that early assessment of their social situation would do much to reduce both their anxiety and the wastage of acute surgical beds.

\section{References}

HuNT, B.L. (1973) The elderly in hospital: recent trends in the use of medical resources. British Medical Journal (Suppl.), $4,83$.

Weaver, P.C. \& Marshall, S.A. (1973) A functional and social review of lower-limb amputees. British Journal of Surgery, 60, 732. 